\title{
Pregnancy and childbirth: Insights for improving malaria, family planning, and maternal and child health outcomes in northwestern Nigeria through social and behavior change programming
}

Breakthrough RESEARCH

Follow this and additional works at: https://knowledgecommons.popcouncil.org/departments_sbsr-rh How does access to this work benefit you? Let us know!

\section{Recommended Citation}

Breakthrough RESEARCH. 2020. "Pregnancy and childbirth-Insights for improving malaria, family planning, and maternal and child health outcomes in northwestern Nigeria through social and behavior change programming," Programmatic Research Brief. Abuja: Population Council. 


\section{Insights for improving malaria, family planning, and maternal and child health outcomes in northwestern Nigeria through social and behavior change research}

\section{Pregnancy and Childbirth}

This brief provides rigorous evidence-based insights to implementers and researchers of social and behavior change (SBC) programs that seek to improve knowledge, attitudes, norms, and behaviors for women during pregnancy and delivery. The brief focuses on women's use of a complete package of antenatal care (ANC) and safe delivery services at health facilities, while also uncovering the barriers and facilitators to these behaviors. It is one of a series that present findings from a Breakthrough RESEARCH study that uniquely captures data on a wide range of psychosocial drivers of behavioral outcomes in the areas of family planning, malaria, and maternal, newborn and child health, and nutrition ( $\mathrm{MNCH}+\mathrm{N})$. The results presented in this series will inform the improvement of women's health in Nigeria and help to achieve the objectives of the Nigerian Reproductive Health Policy, ${ }^{1}$ as well as support global efforts to achieve the United Nations Sustainable Development Goals. ${ }^{2}$

\section{Breakthrough RESEARCH and Breakthrough ACTION in Nigeria}

Breakthrough RESEARCH's study in the northwestern Nigerian states of Kebbi, Sokoto, and Zamfara will inform its sister project Breakthrough ACTION Nigeria, the U.S. Agency for International Development's (USAID's) flagship SBC program, which operates in a total of 11 states and the Federal Capital Territory (FCT) in Nigeria. Breakthrough ACTION, through its messaging and interventions, targets key psychosocial factors at multiple socio-ecological levels (e.g., individual, community, society) that influence decision-making and behaviors to improve women's health. Evidence in this research brief will University

\section{KEY POINTS}

Maternal health during pregnancy is a critical point for interventions in northwestern Nigeria, where the prevalence of ANC use and delivery at a health facility is low and highly inequitable.

Many non-users of maternal health services do not believe that it is necessary to use those services in the absence of sickness or complications, especially in the context of traditional religious beliefs ("It's up to God"). Persuading them otherwise is an SBC challenge.

Among the most important psychosocial factors that influence ANC attendance are a woman's belief in the benefits of ANC, awareness that women should make four or more ANC visits and confidence in her ability to get to a facility for ANC. Focusing messaging on these factors can have significant benefits for women in achieving the recommended number of ANC visits.

SBC programs have great potential for increas- ing women's use of maternal health services. Other things being equal, if SBC programs were to achieve optimal knowledge, beliefs, and other psychosocial influences, ANC use could increase from its current $23 \%$ to over $55 \%$, and facility deliveries could increase from $16 \%$ to $36 \%$ of births.

be used to help adapt and scale-up its programming in Nigeria and elsewhere.

\section{Setting the context}

The low utilization of health services for women remains a challenge in northwestern Nigeria. In 2018, only 54\% of 
women aged $15-49$ years attended ANC during their last pregnancy with far fewer (24\%) attending ANC at least four times (ANC4+). Only $16 \%$ of women delivered in a facility. ${ }^{3}$ Previous qualitative research in Nigeria suggests that barriers to uptake of priority $\mathrm{MNCH}+\mathrm{N}$ services include distance to the health facility, healthcare costs, spousal disapproval, religious influence, and perceived lack of need. ${ }^{4-9}$

Behavioral theories posit the important role of psychosocial factors such as knowledge, norms, values, self-efficacy, and other influences that interact to spur healthy behaviors. ${ }^{9,10}$ This research brief aims to describe different barriers to the use of essential maternal health services, quantify the importance of different ideations on these key behaviors, and model the extent to which SBC programs can effectively change pregnancy and childbirth behaviors by impacting identified psychosocial influences.

\section{Study methods}

Results are based on the Behavioral Sentinel Surveillance (BSS) baseline survey from September to October 2019 (Figure 1).

\section{FIGURE 1 BSS BASELINE SURVEY STUDY METHODS}

\section{Study population \\ Pregnant women and women with under-2s living within Breakthrough ACTION program areas in Kebbi, Sokoto andd Zamfara states (not representative at state level)}

\section{Study}

design

s.s

$\Delta$

Cross-sectional and cohort components

\section{Sample}

size

\#

\#

3,032 pregnant women

3,043 women with a child under 2 years

$\begin{array}{cl}\text { Sampling } & 108 \text { wards across } 3 \text { states } \\ \text { method } & \text { Census of pregnant women } \\ \because \because 0 & \text { Random selection of women with a child under } 2 \\ \because \because & \text { years }\end{array}$

Data

analysis

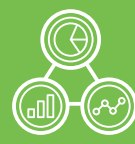

Mixed-effects logistic regression models were used to derive predicted probabilities for ANC4+ (four or more visits) and facility-based delivery, controlling for pregnancy-related ideations and sociodemographic characteristics, including household wealth, age, education (woman and spouse), and employment (woman and spouse).

\section{Key results}

\section{Low and unequal use of ANC4+ and facility-based delivery.}

- Only $23 \%$ of respondents attended ANC4+ and $16 \%$ delivered in a facility during their last pregnancy.

- Women in lower wealth quintiles were $7 x$ less likely to attend ANC4+ or deliver in a facility than those in the top quintiles, leaving them at increased risk of maternal and newborn death and infirmity (Figure 2).

\section{FIGURE 2 WEALTH GAPS IN ANC4+ AND FACILITY-BASED DELIVERY}

Percentage of women 15-49 years who attended ANC4+ or had a facility-based delivery during their last pregnancy, by household wealth quintile

Lowest Second Middle Fourth Highest

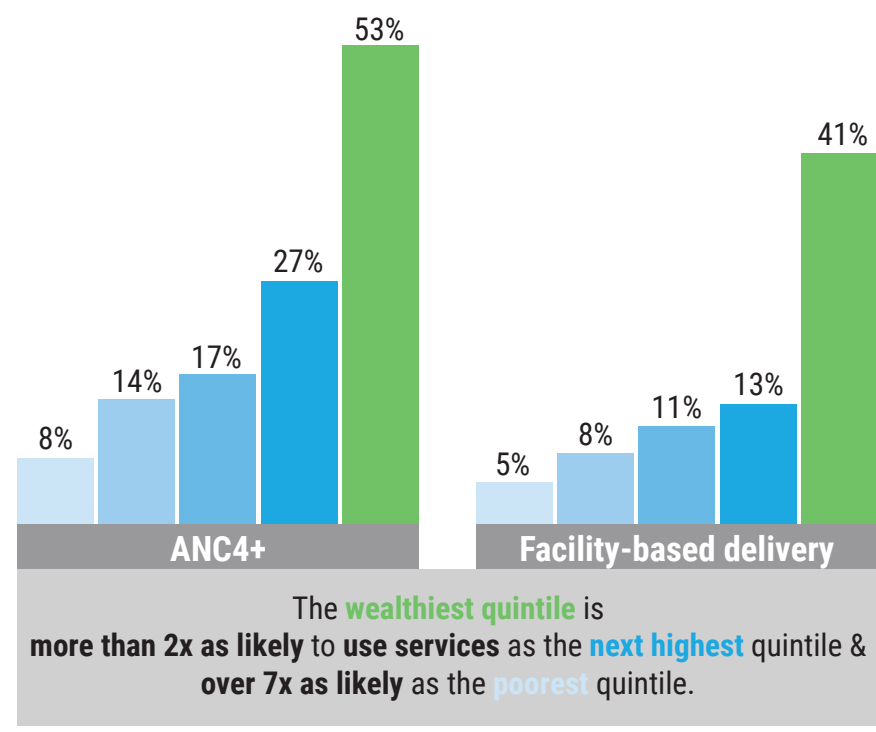

High awareness of the benefits of ANC4+ and facility-based delivery. Most women know that ANC4+ and facility deliveries are beneficial for them and their babies, but they are still not accessing these important services.

- Nearly two-thirds of respondents (62\%) believed that women who attend ANC4+ have safer pregnancies.

- $82 \%$ could identify any ANC benefit, and nearly two-thirds identified monitoring baby's growth and mother's health as specific ANC benefits. However, less than one-third identified specific benefits for preventing malaria in pregnancy or reducing risks of complications.

- Knowledge of ANC benefits was higher among the nonpoor. Women in the wealthiest quintile are $50 \%$ more likely to identify any ANC benefits than women in the lowest quintile. 
- While $54 \%$ agreed that a facility is the best place to deliver a baby, only $16 \%$ of women actually delivered there during their last pregnancy.

\section{Beliefs and social norms are critical barriers to attending ANC4+ and delivering in a facility. Many women believe maternal health services are only needed for sickness or complications.}

- Approximately 4 of 10 respondents who did not attend ANC4+ and two-thirds who did not deliver in a facility reported that services were not necessary (Figure 3).

- About 4 of 10 respondents believed that pregnant women only need ANC if they are sick. Many others believed that ANC4+ and facility-based delivery are not customary, especially in a traditional religious context. Approximately one-quarter who did not use ANC reported that pregnancy outcomes were "Up to God."

- For both ANC and delivery services, less than $10 \%$ reported they did not go because of the distance to the health facility or the cost of services. Almost no one cited poor quality of services as a reason for non-use.

\section{Knowledge of ANC benefits and efficacy are sig- nificantly associated with ANC4+ and facility-based delivery.}

- Women who recognized that ANC has health benefits (knowledge) and knew that woman should attend ANC4+ times (knowledge) were more than twice as likely to attend ANC4+ in adjusted analyses (Figure 4, next page).

- Women who believed that the facility is the best place to deliver a baby (beliefs) and understood that a woman should attend ANC4+ (knowledge) were 2.6 and 1.4 times more likely to deliver in a facility in adjusted analyses (Figure 5, next page).

\section{Programmatic implications}

$\checkmark$ Additional data is needed to identify women who are not aware of the benefits of ANC and facility-based delivery. Targeting their sources of information with positive health-related information would enhance the impact of interventions.

\section{FIGURE 3 "IT'S NOT NECESSARY TO GO"-KEY REASONS FOR NON-USE OF SERVICES}

Percentage of women 15-49 years who did not use ANC or facility-based delivery during their last pregnancy who reported reasons for non-use of these services

Main reasons for no ANC attendance during last pregnancy $(n=1,523)$
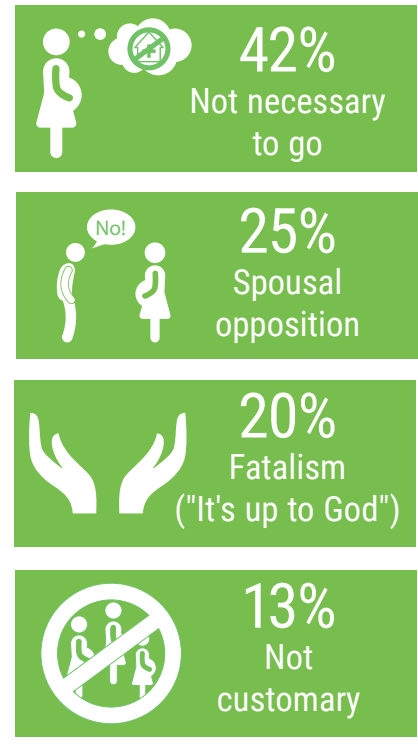

Main reasons for no facility-based delivery for last pregnancy $(n=2,518)$

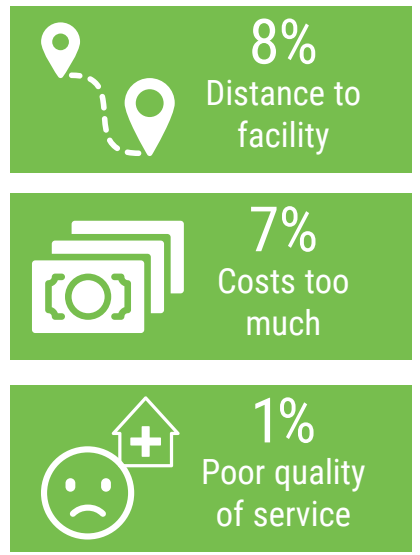

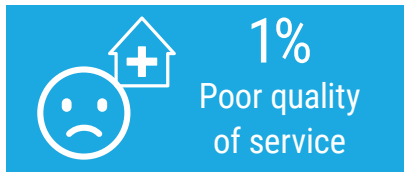
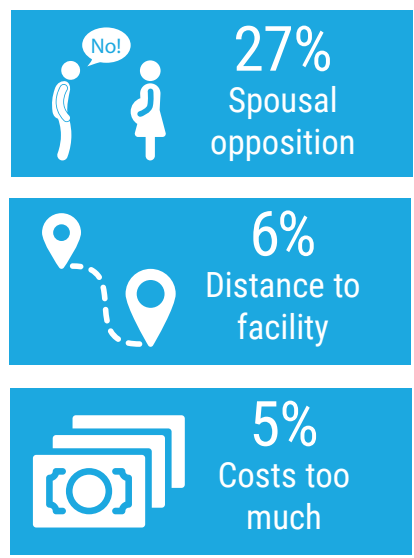
Predicted probabilities* of ANC4+ among women 15-49 years, by ideation (for women's last pregnancy in the past two years)

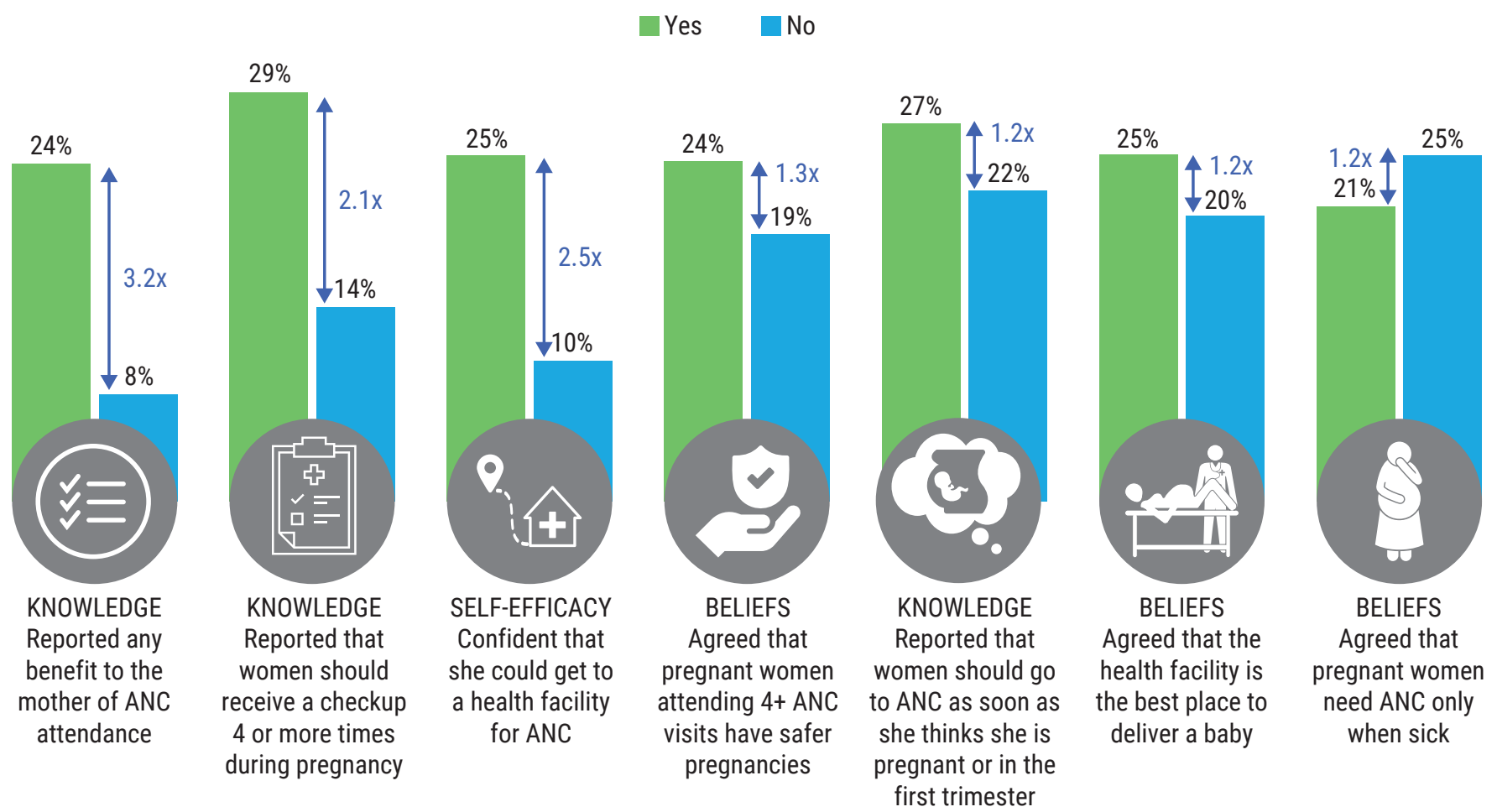

*Predicted probabilities of ANC4+ attendance were derived from mixed-effects logistic regression models adjusted for pregnancy-related ideations (Annex 1) and socioeconomic characteristics including household wealth, woman's age, education (woman and spouse), and employment (woman and spouse). All ideational metrics presented are significant at the $<0.05$ level.

\section{FIGURE 5 PREGNANCY-RELATED IDEATIONS SIGNIFICANTLY ASSOCIATED WITH FACILITY-BASED DELIVERY}

Predicted probabilities* of facility-based delivery among women 15-49 years, by ideation (for women's last pregnancy in the past two years)

*Predicted probabilities of facility-based delivery were derived from mixedeffects logistic regression models adjusted for pregnancy-related ideations (Annex 1) and socioeconomic characteristics including household wealth, woman's age, education (woman and spouse), and employment (woman and spouse).

All ideational metrics presented are significant at the $<0.05$ level.

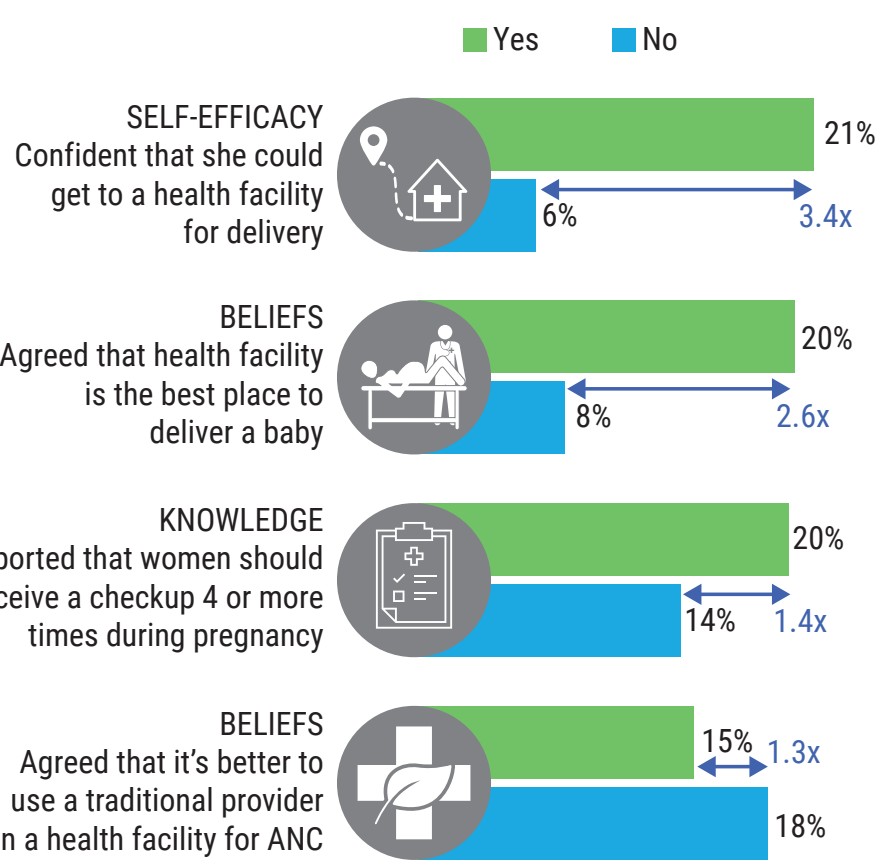




\section{ANC4+ and facility-based delivery is socially influ- enced, especially by spouses and health workers.}

- Women whose husbands supported their decisions were 20\% more likely to attend ANC4+ and 60\% more likely to deliver in a facility. Yet, many women who did not attend ANC4+ or deliver in a facility cited spousal opposition as a principal reason (Figure 3).

- Facility-based delivery was 33\% higher among women who cited health workers as supporting this decision.

- Few women $(<5 \%)$ cited mothers or mothers-in-law as influencers of pregnancy and childbirth decisions.

\section{Programmatic implications}

$\checkmark$ Greater understanding of what causes men to support (or not) ANC4+ attendance and facility - based delivery would help inform project strategies. This research could help identify whether campaigns would be more impactful targeting men or couples.

$\checkmark$ Breakthrough ACTION's Advocacy Core Group model, which enlists religious leaders and influential community members as advocates for using essential MNCH+N services, can serve as an important conduit for shifting norms and influencing the influencers of women's pregnancy and childbirth behaviors.

\section{Empowered women are more likely to attend ANC4+ and deliver in a facility.}

- Women who expressed confidence (self-efficacy) they could get to a facility for ANC or delivery were 2.4 times more likely to attend ANC4+ and 3 times more likely to deliver in a facility in adjusted regression analyses (Figures 4 and 5).

- Poverty inhibits the psychosocial influences that drive uptake of services. Women in the wealthiest quintile were twice as likely to feel confident they could attend ANC4+ than in the poorest quintile (92\% versus $46 \%$ ) and almost 3 times more likely to feel empowered to deliver in a facility $(73 \%$ versus $25 \%)$.

\section{Programmatic implications}

$\checkmark$ Project interventions should work with couples to promote dialogue that will enable women to feel confident in accessing ANC and delivery services.

$\checkmark$ Additional research on the barriers that women perceive could prevent them from getting to a facility could help to shape empowerment campaigns. Research on the downstream behaviors from ANC could also aid in shining light on these barriers.

\section{What is the potential contribution of SBC pro-}

grams? To estimate what SBC programs can potentially achieve in the absence of other changes (e.g. cost off services or other factors remain at their current levels), we conducted regression analyses assuming hypothetical scenarios in which every woman is confident that she can get to a health facility, knows the benefits of ANC, receives spousal support for attending ANC4+, and believes that health facilities provide high-quality services.

Figure 5 (next page) presents actual ANC4+ use compared to the results of simulations that predict ANC4+ use assuming improved knowledge and perfect ideation, by wealth quintile. $^{1}$

Scenario 1: The SBC program achieves improved knowledge. All women know when to go for ANC, know how many visits to make, and can identify any benefits of attending ANC4+. In this scenario, ANC4+ increases from the current 23\% to $36 \%$ - a more than $50 \%$ increase. This is, of course, good but SBC programs can do better.

Scenario 2: All women have improved knowledge but also receive spousal support, believe that it is important to discuss pregnancies with a husband, and are confident about getting to a health facility. In this scenario, ANC4+ attendance would increase dramatically, and the effects would be largest for those in the poorest quintiles. In absence of other changes, the maximum effect of SBC programs is to increase ANC4+ attendance from the current $23 \%$ to $55 \%$, more than doubling the percentage of women attending ANC4+.

Figure 6 (next page) presents a similar analysis for facility-based delivery. Again, the simulations show that if SBC programs were to achieve improved knowledge,

facility-based delivery would increase from the current $16 \%$ to $21 \%$, or a roughly $33 \%$ increase. However, if SBC program were to succeed in achieving improved ideation in addition to improved knowledge, the percentage of women delivering in a facility would increase quite substantially-from the current $16 \%$ to $37 \%$. The benefits would most affect those in the poorest quintiles with a seven-fold increase for those in the poorest quintile and a 4.5-fold increase for those in the second poorest quintile. This would be remarkable, but nonetheless, nearly two-thirds of women would still not deliver in a facility.

As achieving perfect ideation is unrealistic, the actual effects of SBC programs on $\mathrm{MNCH}+\mathrm{N}$ outcomes and that achieved through perfect ideation represent boundaries between which SBC programming could enhance $\mathrm{MNCH}+\mathrm{N}$ outcomes.

${ }^{1}$ In these simulations, we estimate the predicted probability of ANC4+ when all of the psychosocial influences are assumed to be positive (e.g., is able to identify benefits of ANC, agrees that pregnant women who attend 4+ ANC visits have safer pregnancies), referred to as "perfect ideation" in this analysis. 

ANC4+ ATTENDANCE, BY WEALTH QUINTILE

Predicted probabilities* of making 4+ ANC visits during the most recent pregnancy if all statistically significant psychosocial influences are assumed to be positive ("perfect ideation") by wealth quintile

Actual aNC with improved knowledge $\quad$ ANC4+ with improved ideation

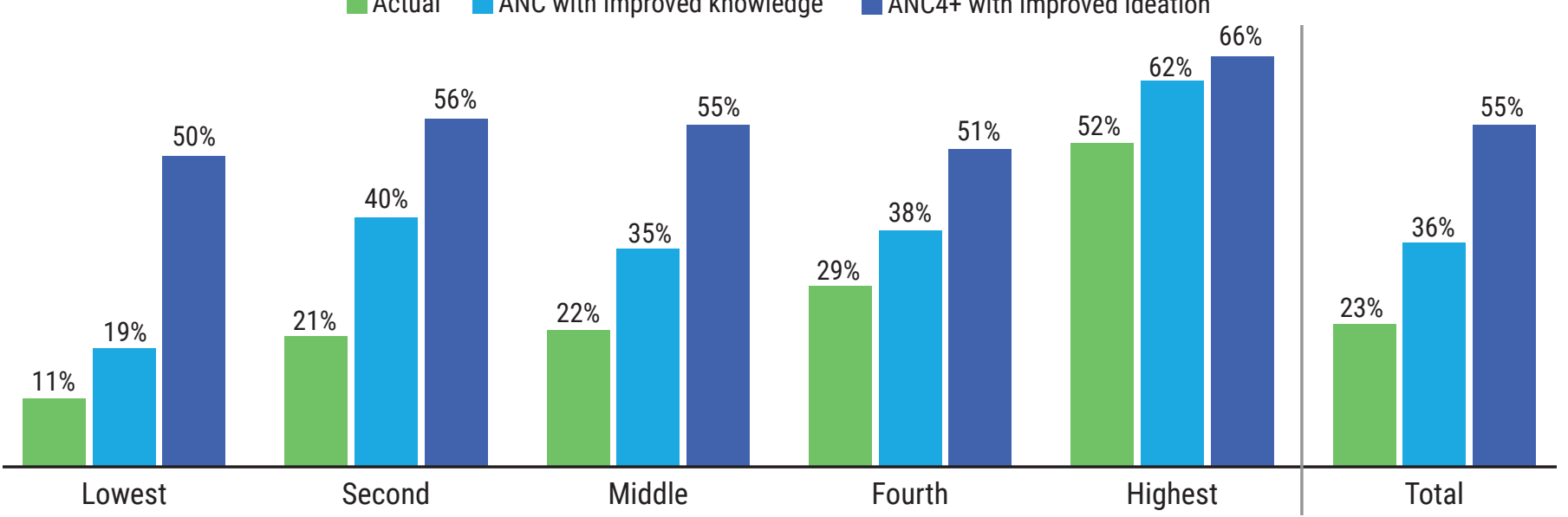

*Predicted probabilities of ANC4+ were derived from mixed-effects logistic regression models adjusted for pregnancy-related ideations (Annex 1) and socioeconomic characteristics including household wealth, woman's age, education (woman and spouse), and employment (woman and spouse) based on a scenario where all statistically significant psychosocial influences on ANC4+ visits are assumed to be positive.

\section{FIGURE 6 SIMULATION OF THE POTENTIAL EFFECTS OF IMPROVED KNOWLEDGE AND IDEATION ON FACILITY DELIVERIES, BY WEALTH QUINTILE}

Predicted probabilities* of delivering in a facility during most recent pregnancy if all statistically significant psychosocial influences are assumed to be positive ("perfect ideation") by wealth quintile

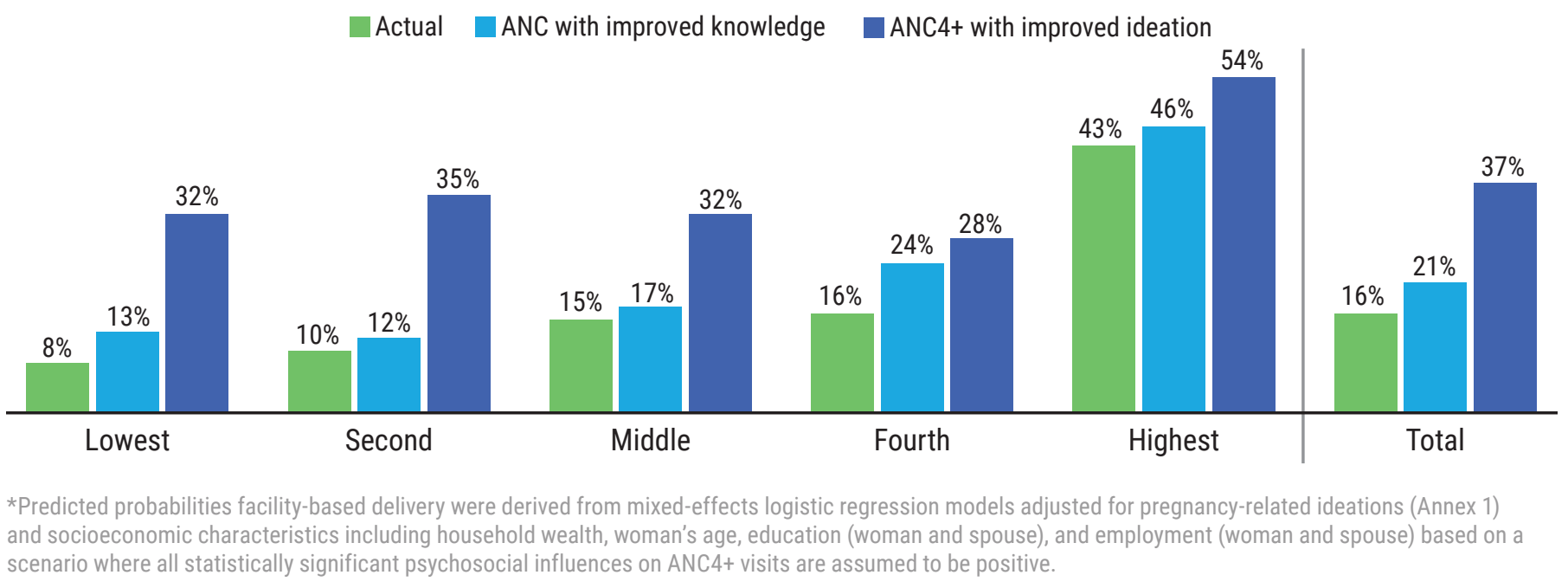




\section{Conclusion}

The results indicate an important role for SBC programming in northwestern Nigerian and its potential to achieve substantial improvements in the use of essential maternal health services, even in the absence of other changes. To this end, findings also indicate the most important ideations for SBC programs to address in order to better target their activities to improve pregnancy and childbirth behaviors.

Results show the importance of women's knowledge about ANC timing, benefits and efficacy for the uptake of ANC4+ and facility-based delivery. Yet knowledge alone is not sufficient. Women also need to benefit from the support of husbands and from an environment in which using maternal health services is an accepted norm, and where women feel empowered to access these services.

Simulations further suggest that SBC programs alone could potentially increase ANC4+ from $23 \%$ to $55 \%$, and facility-based delivery from $16 \%$ to $37 \%$ in northwestern Nigeria, with greatest increases among the poorest women. Although it is not expected that SBC programs will be able to achieve perfect knowledge and ideation, at least in the short term, the simulations indicate that even more modest changes in ideation are likely to have a substantial effect on use of these essential maternal health services.

\section{Annex 1: Pregnancy-related ideational metrics}

\section{DIMENSION \\ DOMAIN \\ QUESTION OR LIKERT-SCALE STATEMENT}

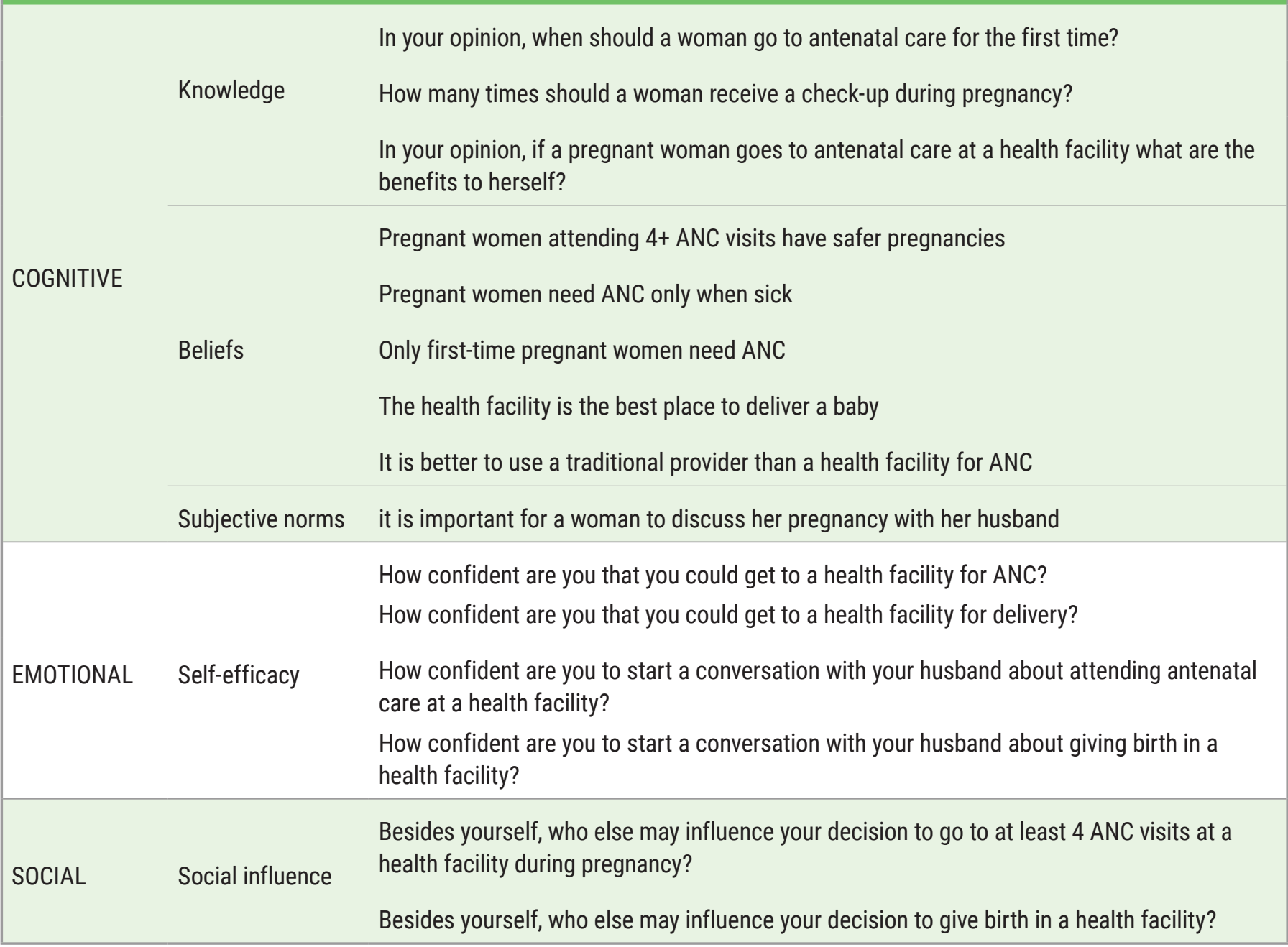




\section{References}

1. Federal Government of Nigeria. 2019. National Strategic Health Development Plan II (NSHDP) 2018-2022. Abuja: Nigeria: Federal Government of Nigeria.

2. Government of Nigeria. 2017. Implementation of the SDGs: A National Voluntary Review, Abuja FCT, Nigeria.

3. National Population Commission (NPC) and ICF International. 2019. Nigeria Demographic and Health Survey 2018. Abuja, Nigeria and Rockville, MD, USA: NPC an ICF.

4. Breakthrough ACTION/Nigeria. 2018. "MNCH+N Insights Report: How might we radically improve $\mathrm{MNCH}+\mathrm{N}$ in Northern Nigeria."

5. Adamu, Y.M. and H.M. Salihu. 2002. "Barriers to the use of antenatal and obstetric care services in rural Kano, Nigeria." Journal of Obstetric Gynaecology 22(6): 600-3.

6. Doctor, H.V. et al. 2012. "Using community-based research to shape the design and delivery of maternal health services in Northern Nigeria," Reproductive Health Matters 20(39): 104-12.

7. Fagbamigbe, A.F. and E.S. Idemudia ES. 2015. "Barriers to antenatal care use in Nigeria: evidence from non-users and implications for maternal health programming," BMC Pregnancy and Childbirth 15: 95.

8. Ishola, G. et al. 2017. "Effect of volunteer household counseling in improving knowledge of birth preparedness and complication readiness of pregnant women in Northwest Nigeria," African Journal of Reproductive Health 21(1): 39-48.

9. Fetohy, Ebtisam M. 2004. "Impact of a simple health education program about antenatal care on knowledge, attitudes, subjective norms and intention of pregnant women," Journal of Egypt Public Health Association 79: 283-310.

10. Ajzen, I. 1985. "From intentions to actions: a theory of planned behavior." In: Kuhl J, Beckmann J. (eds) Action Control. SSSP Springer Series in Social Psychology. Berlin: Springer.

11. Kincaid, D.L. 2000. "Mass media, ideation and behavior: A longitudinal analysis of contraceptive change in the Philippines," Communication Research 27: 723-763.

\section{Acknowledgments}

This programmatic research brief describes work led by Tulane University under Breakthrough RESEARCH. This brief and the work it describes is possible through the work and support of the Center for Research, Evaluation Resources and Development (CRERD), Breakthrough ACTION in Nigeria, Population Reference Bureau, and Population Council in Washington, DC.

\section{Suggested citation}

Breakthrough RESEARCH. 2020. "Pregnancy and childbirthInsights for improving malaria, family planning, and maternal and child health outcomes in northwestern Nigeria through social and behavior change programming," Programmatic Research Brief. Abuja, Nigeria: Population Council.

(C) 2020 The Population Council. All rights reserved.

\section{Email}

\section{BreakthroughResearch@popcouncil.org}

\section{Breakthrough RESEARCH | Population Council}

Plot 839 Idris Ibrahim Crescent | Jabi, Abuja, Nigeria +2348067787750

4301 Connecticut Ave., NW, Suite 280 | Washington, DC 20008 +12022379400 | breakthroughactionandresearch.org

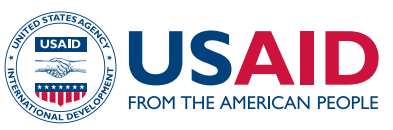

Breakthrough RESEARCH is made possible by the generous support of the American people through the United States Agency for International Development (USAID) under the terms of cooperative agreement no. AIDOAA-A-17-00018. The contents of this document are the sole responsibility of Breakthrough RESEARCH and Population Council and do not necessarily reflect the views of USAID or the United States Government.
POPULATION COUNCIL

Ideas. Evidence. Impact.

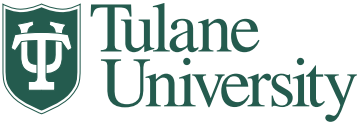

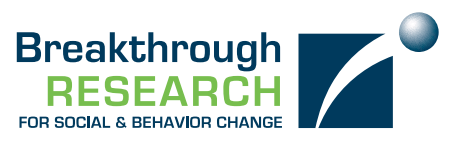

Our project turns evidence into action by providing thought provoking guidance to improve SBC policy and programming, with the goal of improving the cost-effectiveness of USAID's health and development strategies. Breakthrough RESEARCH catalyzes SBC by conducting state-of-the-art research and evaluation and promoting evidence-based solutions to improve health and development programs around the world. Breakthrough RESEARCH is a consortium led by the Population Council in partnership with Avenir Health, ideas42, Institute for Reproductive Health at Georgetown University, Population Reference Bureau, and Tulane University. 